\title{
Current and Future Perspective of Biotechnological Applications in Livestock Nutrition: A Review
}

\author{
Dharmendra Chharang ${ }^{1}$, Vijay Prakash Saini ${ }^{1}$, Deepak Chopra $^{2}$ and \\ Sheela Choudhary ${ }^{1}$
}

${ }^{1}$ Department of Animal Nutrition, Post Graduate Institute of Veterinary Education and Research, Rajasthan University of Veterinary and Animal Sciences, Agra Road, Jamdoli, Jaipur (Rajasthan)-302031, India

${ }^{2}$ Department of Livestock Production and Management, Lala Lajpat Rai University of Veterinary and Animal Sciences, Hisar (Haryana), India

*Corresponding author

\section{A B S T R A C T}

\begin{tabular}{|c|}
\hline Keywords \\
\hline $\begin{array}{l}\text { Augmentation, Bio- } \\
\text { preservation, } \\
\text { Biotechnology, } \\
\text { Chelated, } \\
\text { Deamination, } \\
\text { Gluconeogenesis, } \\
\text { Inoculation, } \\
\text { Methanogenesis, } \\
\text { Recombinant, } \\
\text { transgenic }\end{array}$ \\
\hline Article Info \\
\hline $\begin{array}{l}\text { Accepted: } \\
10 \text { May } 2019 \\
\text { Available Online: } \\
10 \text { June } 2019\end{array}$ \\
\hline
\end{tabular}
producers.
Biotechnology is one of the leading areas of scientific development in the world today. In order to improve the overall life standard of

human, there has been progress in the field of

\section{Introduction}

Biotechnology plays an important role in improving the quality of livestock products as well as ensuring their safety from consumer perspective. Biotechnology has the potential to provide new opportunities for achieving increased livestock productivity. It provides a range of tools to advance our understanding, management and utilization of crop and livestock resources for various social and economic benefits of human being. Biotechnology in animal production in developing nations has been applied only in a certain areas such as animal improvement, healthcare, conservation, and augmentation of feed resources. Modern biotechnology is one of the leading areas of scientific development in the world today. In order to improve the overall life standard of human, there has been progress in the field of biotechnology in a wide area of science i.e. animal science, agricultural science, medical science, environmental science, food science, etc. Adopting biotechnology has benefited in livestock improvement and economic returns to the livestock entrepreneurs and small biotechnology in a wide area of science i.e. animal science, agricultural science, medical science, environmental science, food science, etc. This area of science is becoming a permanent means of improving livestock production by affecting animal health, 
nutrition, production, genetics and reproduction (Bonneau and Laarveld, 1999). The main obstacle for the successful application of biotechnology is related to the cost of adoption and acceptability (Kahi and Rewe, 2008). To improve living organisms or their derivatives or to better multiply a product, the application of real biological principles is biotechnology in simple tools. This term can be broadly defined as the technique by which useful products can be produced from raw materials with the help of organisms or other biological processes. Biotechnology tools can be applied in the production of high-yielding animals, improving the quality characteristics of animal origin, production of hormones, functional and designer livestock products, enzymes, bio-preservation of livestock products, efficient by product utilization, quality control and meat authentication. Biotechnology plays an important role in improving the quality of livestock products as well as ensuring their safety from consumer perspective (Gupta and Savalia, 2012). Chronic feed deficits represent a major constraint to animal production in developing and underdeveloped countries due to the increasing human and livestock population and their activities continue to impose tremendous pressure on available resources. The situation manifested itself in poor animal performance, low growth rate, reduced reproductive efficiency etc. Thus, to alleviate the extremely alarming multidimensional nutritional crisis for livestock multi directional approaches involving utilization of new feed resources in combination with suitable technologies improving efficiency of utilization of these resources are probably the most viable proposition in this regard (Chharang, 2004).

In recent years, the development of biotechnology has allowed the use of nontoxic fungi, in which fibrous feed such as straw or poor quality roughage can be improved. In particular, white rot fungi have been used due to their ability to delignify the plant's material. In addition to antibiotics, a wide variety of feed additives, are known for modifying rumen fermentation. They contain components that can reduce methanogenesis, increase propionic acid production, reduce protein degradation, improve microbial protein synthesis and inhibit protozoa. Such additives contain specific substrates, such as antibiotics, microbes, and oligosaccharides. In addition, the effective enzyme preparation can now be produced in large quantities and relatively inexpensively. Therefore, supplement of diet as a means of improving nutritional value is becoming common. The ultimate goal of using biotechnology in animal nutrition is to improve the nutritional plan by increasing the availability of nutrients from the feed and reducing the wastage of feed (Asmare, 2014). Modern biotechnology has the potential to provide new opportunities for achieving increased livestock productivity, which reduces poverty, improves food security and nutrition and promotes the sustainable use of natural resources (Leng, 1991).

\section{Biotechnology in forage breeding}

Genetically engineered forage crops, with a range of potential benefits for production, human health and the environment, are genetically modified using recombinant DNA technology with the purpose of introducing a desirable characteristic in the plant or seed. The purpose of these transgenic forage crops is to provide many benefits to consumers, as well as developers and producers. Products consumed by humans, derived from animals fed on transgenic forage crops are not themselves transgenic. Thus, food products obtained from animals fed on transgenic forage crops offering human health benefits may receive various levels of support from 
the public than the currently available set of transgenic food crops (Spangenberg et al., 2001).

It is known that forest legumes are relatively low in sulfur-rich amino acids, and their availability for ruminants is further adversely affected during rumen digestion (Croissant $e t$ al., 1976). This leads to the lack of optimum of essential amino acids for animal growth level. Plant genetic modification, with gene encoding for a sulfur amino acid-rich protein, resistant to rapid rumen degradation can compensate this deficiency. Studies (Phipps et al., 2005) showed that inclusion of genetically modified feed ingredients in the dairy cow diet did not have any effect on feed intake or milk production.

\section{Biotechnology for fibrous feed improvement}

Fibrous feeds of low digestibility include the major proportion of feeds accessible to most ruminants under smallholder situations in developing countries (Lebbie and Kagwini, 1996). It is well known that some microorganisms, including cellulose enzymes from anaerobic bacteria and white rot fungi (Pleurotus ostreatus) can degrade lignin in the cell walls. Several fungal strains have been used for lingo-cellulosic hydrolysis such as Asprigullus niger, A. terreus, Chaetomium celluloyticum, and Fusarium moniliforme (Kim et al., 1985). However, among many species of fungi such as white rot fungi have the ability to treat the roughages as they attack the lignin polymers, open the aromatic rings and release low molecular weight fragments.

Another indirect approach to the increase of fibre digestion in ruminants is through the modification of silage Inoculants. In silage containing low carbohydrate contents, to increase lactic acid production by releasing sugars for the growth of lactobacilli, enzymes such as amylase, hemicellulase or cellulase are included. Thus, to produce such enzymes, inoculation of genetically modified silage bacteria has been proposed to obtain better ensiling which ultimately leads to better rumen digestibility.

\section{Bypass nutrient technology}

Protected nutrient technology is an approach that involves feed management through passive rumen manipulation, through which dietary nutrients (fat and protein) are protected from hydrolysis, by which these nutrients are able to bypass the digestion in rumen, and get digested and then absorbed from lower tract. Protected nutrients contain primarily protected fat and proteins and are also known as bypass nutrients. Other protected nutrients are protected starch, chelated minerals and vitamins (Shelke et al., 2012).

\section{Bypass protein technology}

When highly degradable protein-rich oil cakes are ingested by ruminants, which results in production of ammonia extensively, most of which gets wasted in the form of urea excreted through urine. Even animal has to spend energy to convert ammonia into urea in the liver. In order to increase the efficiency of utilization of proteins from the highly degradable cakes, these proteins are required to protect from excessive ruminal degradation and can be used as protected proteins, so that the amino acids from these protein feeds are absorbed intact from intestines of the animal for the process of gluconeogenesis in the liver as well as for tissue protein synthesis (Walli, 2005). Appropriate technological methods such as chemical, physical, or combinations of both, for the proteinous feeds and their byproducts can be employed before their inclusion in the rations of ruminants for 
improving productivity. Among various processing methods, heat treatment like extrusion cooking and dry roasting techniques can be used to improve the digestibility and utilization of proteinous and other feeds by ruminants. Chemical treatment has also been used to protect proteins and for this formaldehyde treatment has been the most effective and viable technique for the bypass protein production. Only a few feeds are considered good sources of naturally occurring protected protein, having lower protein degradability viz., maize gluten meal, maize grain, cottonseed cake, fish meal, and coconut cake. Feeds like linseed cake, deoiled rice bran, and soybean meal are of medium protein degradability, while Groundnut Cake (GNC) and Mustard Cake (MC) are highly degradable cakes (Negi et al., 1989; Walli, 2005; Shelke et al., 2011).

\section{Bypass fat technology}

Protected fats can be obtained in various ways such as the formation of calcium salt of fatty acids and encapsulation technique. Adding protected fat to dairy rations can positively affect efficiency of dairy cows through a combination of caloric and non-caloric effects. Caloric effects are attributable to higher energy content and energetic efficiency of lipids as compared to proteins or carbohydrates with the overall benefit being increased milk production and the persistency of lactation. The main sources of short chain fatty acids (SCFA) are cotton seed oil and palm oil. All sources of fat have a substantial amount of long chain fatty acid (LCFA). The main sources of linolenic acid (C18: $3 n 3)$ are flaxseed, hemp, soybean, canola, nuts and dark green forages.

\section{Biotechnology products as feed additives}

Feed additives are materials that are administered to the animal to increase the effectiveness of nutrients and exert their effects in the gut (Fuller, 1989). Feed additives include enzymes, antibiotic, prebiotics and probiotics (McDonald et al., 2010).

\section{Enzymes}

As a result of advances in biotechnology, more effective enzyme preparations can now be produced in large amounts and relatively inexpensive (McDonald et al., 2010). Therefore, the supplement of diet as a means of improving nutritional value has become common. The enzymes used as food additives work in many ways. According to studies, the enzymes are mainly used in non-ruminants' diet, but are also added in the ruminants' diet (Fuller, 1989). Their main objective is to improve the nutritional value of the diet, especially when poor quality, and usually less expensive, ingredients are added.

The common example of enzymes is the use of phytase feed enzyme in monogastric diets. Phytase feed enzymes have more general applications as their substrates are invariably available in poultry and pig diets and their dietary inclusion generates bio-available phosphorus, economically and reduces phosphorus load on the environment.

Amino Acid digestibility may also be improved even with phytase supplementation. In ruminant nutrition, enzymes improve the availability of plant storage polysaccharides (e.g. starch), proteins and oils, which are protected from digestive enzymes by the impermeable cell wall structures.

Thus, cellulases can be used to break down cellulose, which is not degraded by endogenous mammalian enzymes. Enzymes are essential for the breakdown of cell wall carbohydrates to release the sugars necessary for the growth of the lactic acid bacteria. 


\section{Antibiotics}

Antibiotics are antimicrobial medicines, usually fungal or plant, and are synthesized in the laboratory (Fuller, 1989). Although the primary use of antibiotics is in the treatment of infection, some antibiotics are used as feed additives to improve growth and feed conversion efficiency. Among antibiotic groups contain ionophores, which are used in animals such as ruminants, which improve feed efficiency by shifting rumen fermentation towards the production of more propionic acid, which can be used by animals and less methane, which is lost (McDonald et al., 2010). Ionophores hereby change the pattern of rumen microorganisms, reduce the production of acetate, butyrate and methane, and increase the proportion of propionate (McDonald et al., 2010 and McGuffey et al., 2001). Since methane is a waste product, the efficiency of rumen activity is improves. Ionophores also reduce the total mass of bacteria and thereby decrease the amount of dietary protein degraded.

\section{Prebiotics and probiotics}

Probiotics are feed supplements that are incorporated to the diet of farm animals to improve microbial balance of intestine (Fuller, 1989). In contrast to the use of antibiotics as nutritional modifiers, which destroy bacteria, the inclusion of probiotics in feeds is designed to encourage certain strains of bacteria in the intestine at the expense of less desirable ones (McDonald et al., 2010). Apart from this, these microorganisms are responsible for production of vitamins of the B complex and digestive enzymes, and for stimulation of intestinal mucosa immunity, increase protection against toxic substances produced by pathogenic microorganisms. Among ruminants, they are more effective in controlling the diseases of the gastrointestinal tract of young animals, as there is no complication of the rumen micro-flora. The initial colonization of the small intestine is from the dam's microflora and the immediate surroundings, and usually includes E. coli, streptococci, and Clostridium welchii. When milk feeding commences, the lactobacilli become the predominant bacteria present. Calf probiotics have benign lactobacilli or streptococci and are likely to be valuable only when given to calves that have suffered stress or have been treated with antibiotics that have destroyed the natural microflora (Fuller, 1989). Addition of probiotics to the diet produces variable benefit, depending on whether the animals are in poor health. Dry yeast (Saccharomyces cerevisiae) has the advantage over bacterial probiotics that it is more tolerant of extreme environmental conditions and $\mathrm{pH}$. The use of probiotic is subject to extensive legislation designed to protect farm animals and consumers. In adult ruminants yeasts may be used as probiotics to improve rumen fermentation (Fuller, 1989). The most common prebiotics are oligosaccharides, which are non-digestible carbohydrates.

\section{Rumen manipulation technology}

Broadly the techniques of rumen manipulation can be classified in two categories i.e. genetic and non genetic manipulation. In genetic manipulation, rumen microbes are genetically engineered by gene transfer technique to enhance the animal productivity whereas non genetic manipulation of the rumen can be done by dietary manipulation.

\section{Defaunation in ruminants}

Protozoa, unlike bacteria, is not important for the development and survival of the ruminant hosts, and their elimination (defaunation), although producing a less stable rumen environment, has been found to reduce 
gaseous carbon and nitrogen losses (Fuller, 1989). It has been established that ruminants can survive with or without these organisms; however, manipulation of their population may affect protein metabolism in the rumen (Wael et al., 1998). It enhances the synthesis of microbial proteins in rumen as the bacteria make up the main source of protein for protozoa. Defaunation often results in reduction in production of VFA and it is associated with reduction in proportion of butyrate to the advantage of propionate or acetate in the mixture of VFA. It also reduces the methanogenic activity of rumen by decreasing energy losses, can be of considerable benefit to animals with a high production potential (Jouany, 1994).

\section{Genetic manipulation of microbes}

The possibilities for application of molecular techniques are very high in achieving the goals of the rumen manipulation (Forano, 1991; Flint 1994; Wallace, 1994). This technique may allow the introduction of desired activities like cellulolysis and detoxification, or to reduce undesirable activities such as proteolysis, deamination and methanogenesis. For this purpose, one approach is to select desirable genes and to express them in predominant rumen bacteria. Naturally present microorganisms in the rumen can be genetically modified to enhance their ability to defined functions or to add new functions (Chang, 1996). Introduction of diversified genes in intestinal microorganisms have been extensively explored (McSweeny et al., 1999). Genetically modified microorganisms are either able to digest lignin of fibrous components, or degrade toxic substances, reduce ruminal methane production, synthesize essential amino acids, and tolerate acids (Forsberg et al., 1993). The first step in the process of genetic modification of rumen microbes is to select the desired gene, which is to be engineered, i.e., if the cellulose degradation is to be improved, the bacteria which are deficient in cellulose degradation should be selected. Fibrobacter succinogens, which make succinic acid as one of the end products of cellulose fermentation, is one such example. These bacteria can be modified to have a large number of genes for cellulose degradation so that cellulose degradation in the rumen becomes increased. After selecting the desired genes, a suitable vector is required to carry the gene to the recipient cell. One of the most important vectors is plasmid, which has extra chromosomal genetic material which is unable to integrate with chromosomal genetic material and remains autonomous and dispensable. Some rumen bacteria have also been shown to harbour plasmid (Smith and Hespell, 1983). Plasmid of rumen bacteria can be recombined with the desired gene bacteria. Recombined plasmid is then transferred back into the rumen bacteria to facilitate the insertion of desired genetic property. It is always recommended to use a shuttle vector which has two replication origin and are able to replicate in two host species. Thus, genetic manipulation can be done in bacteria, easy to handle e.g. Escherichia coli and then transfer the recombined genetic material into rumen bacteria, which can be used for practical application (Santra and Karim, 2003).

\section{Biotechnology in modified milk, meat and eggs}

Recent achievements of biotechnology have emerged as a powerful tool to improve the quality characteristics of livestock products including milk and meat products. Biotechnological approaches can be employed for improving economy, productivity, physicochemical and nutritional attributes of a wide range of livestock by products. The target areas of biotechnology research in the field of livestock products can 
be envisaged in the production of high yielding food animals, improvement in quality of their products, increase in the production of natural food grade preservatives, efficient by product use and so forth. Many of the biotechnology technologies can be explored in the field of quality assurance programs, which would be of great help in ensuring quality and public health safety in the production of livestock products (Gupta and Savalia, 2012).

With recent developments in biotechnological techniques, e.g. genetic engineering, rDNA technology, protein engineering and advances in animal cloning and transgenic techniques, it is now possible to alter animal byproducts composition at will for better technological properties to add variety to our traditional products and also to produce variants of milk, meat and eggs to meet the needs of specific consumers from health and nutritional perspectives. With the advent of modern gene transfer and methods of expression, new opportunities have been created for the modification of animal production traits, including the production of milk, meat and eggs with altered composition.

Health-conscious consumers are demanding quality animal byproducts and are ready to pay premium price. This leads to the development of designer food items. Designer foods are also called as fortified, functional, enriched or nutraceuticals or value added food items. In addition to providing basic nutritional benefits, designer foods have a good effect on health. Designer milk, eggs and meat can be produced by nutritional manipulation of animal diets, also, i.e. addition of various components promoting health, such as antioxidants, omega fatty acids, minerals, vitamins and various nonnutrient additives. Altered fatty acid profiles specifically the enrichment of egg and meat with omega 3 fatty acids, lowering of cholesterol and other compositional components such as conjugated linoleic acid, lutein, selenium, choline, and vitamins B, D, $\mathrm{E}$ and $\mathrm{K}$, are produced now days (Sahoo and Jena 2014).

Therefore, animal byproducts like meat, eggs and milk can be modified either by genetic or dietary manipulation i.e. by incorporating required functional ingredients directly into animal products or modifying the feed formulation of the host animal to get desired composition in products of animal origin i.e. meat, eggs and milk.

\section{Nanobiotechnology}

Nanotechnology is a promising and emerging technology that has tremendous potential for revolution in the animal sector as well as all over the world. The word nanotechnology is derived from the Latin word "nanus", which means dwarf Nano-particles generally have dimensions between about 1 and 100 nanometers. So these nano-particles can bypass the physiological ways of nutrient distribution and transport across tissue and cell membranes, and have more bioavailability to the target sites. Nanotechnology is an innovative technology that ultimately alters the structure of foodstuff and enhanced quality, texture at the molecular level. This technique has major impact on the production, processing, storage, safety, security, and transport of food for both humans and animals. Recently, trace minerals in the form of nano-particles are effectively used to meet the requirement of minerals in the animal diets. Due to their extreme small size and unique physical properties, nano-particles are likely to be different in comparison to their conventional forms. As a feed additive, these are expected to have the advantage of better bioavailability, small dose rate and stable interaction with other components. The nano form of supplementation increases the surface 
area, which can possibly increase the absorption, and by which the utilization of minerals leading to reduce the amount of supplement and ultimately to decrease the feed cost (Vinus and Sheoran, 2017).

\section{Solid-State Fermentation Technology}

Solid-state fermentation has long been applied to the food industry. The concept of using solid substrate is probably the oldest method that humans use microorganisms to work for them. In recent years, SSF has made a lot of promise in the development of many bioprocesses and products. SSFs are processes carried out with microbes growing on nutrient impregnated solid substrate with less or no free water. SSF is alternative to submerged fermentation to produce valueadded products like antibiotics, single cell proteins, poly unsaturated fatty acids, enzymes, organic acids, bio-pesticides, biofuels and aroma production. The purpose of SSF is to bring the fungus or bacteria cultivated in tight contact with the insoluble substrate and achieve the highest nutrient concentration from the substrate for fermentation. This technique so far is run on a small scale till now, but there is an advantage over submerged fermentation. However, there are several major constraints in the development of SSF on industrial scale, including the mass and heat transfer limitations and difficulty in handling solids in existing reactors and the lack of kinetic and design data on various fermentations. The main problem is that the development of a simple and practical automated fermenter for SSF processes has not yet been achieved (Bhargav, 2008).

For SSF processes, various agro-industrial wastes are used as solid substrates. Selection of agro-industrial residues for use in SSF depends on some physical parameters such as particle size, moisture level, intra-particle spacing and nutrient composition within the substrate. In recent years, some important agro-industrial residues such as cassava bagasse, sugarcane bagasse, sugar beat pulp/husk, orange bagasse, oil cakes, apple pomace, grape juice, grape seed, coffee husk, wheat bran, coir pith etc. have been used as substrates for solid-state fermentation.

\section{Future perspective}

In order to promote improvements in current and future global livestock production, it is necessary to adopt new biotechnological applications and bio-safety in livestock nutrition and feeding systems. Future improvements in livestock feed resources could be based on the application of biotechnology such as the use of safe antibiotic replacers. Prebiotics and probiotics could be employed to improve the performance of livestock. The risks involved in the use of antibiotics and the development of antibiotic resistance in livestock and in humans should be kept at minimum levels. Further, the expectations about the future improvement in livestock feeding could involve the application of nanoparticles in livestock feeds and feeding to enhance livestock nutrition, growth, health and performance.

In conclusion, biotechnology plays an important role in improving the quality of livestock products as well as ensuring their safety from consumer perspective. Biotechnology is a support for different areas of agricultural production and processing. Fibrous feeds, including crop residues having low digestibility constitute the major proportion of feeds available to most animals under smallholder conditions in developing nations. The associated low productivity can be overcome to certain extent by various means, among which are, balancing of nutrients for the growth of rumen microbes 
thereby facilitating efficient fermentative digestion and providing small amount of bypass nutrients to balance the products of fermentative digestion, improving digestibility of fibrous feeds through treatment with alkali or by manipulating the balance of organisms in the rumen and genetic manipulation of rumen micro-flora, currently acknowledged as potentially the most powerful tool for improving the rate and extent of digestion of low quality feeds. Rumen micro-organisms can also be manipulated by providing antibiotics as feed additives, fats to eliminate or reduce rumen ciliate protozoa i.e. defaunation, protein degradation protectors, buffer substances, methane inhibitors, rumen content and branched chain volatile fatty acids. It is now possible to alter animal byproducts composition at will for better technological properties to add variety to our conventional products and also to produce variants of milk, meat and eggs to meet the needs of specific consumers from health and nutritional perspectives. Nanotechnology is an innovative technology that ultimately alters the structure of foodstuff and enhanced quality, texture at the molecular level. This technique has major impact on the production, processing, storage, safety, security, and transport of food for both humans and animals. SSF technology has long been applied to the food industry, has shown much promise in development of several bioprocesses and products. The ultimate goal of using biotechnology in animal nutrition is to improve the plane of nutrition through increasing availability of nutrients from feed and to reduce the wastage of the feed.

\section{References}

Asmare, B. (2014). Biotechnological Advances for Animal Nutrition and Feed Improvement. World Journal of Agricultural Research, 2014, Vol. 2, No. 3, 115-118.

Bhargav S. et al., (2008). Solid-state
Fermentation: An Overview, Chem. Biochem. Eng. Q. 22(1): 49-70 (2008).

Bonneau, M. and Laarveld, B. (1999). Biotechnology in animal nutrition, physiology and health. Livest. Prod. Sci. 59: 223-241.

Chang, H. (1996). Genetic engineering to enhance microbial interference and related therapeutic applications. Nature Biotecnol. 14:423-431.

Chharang, D. (2004). Effect of replacement of barley and cotton seed cake by mesquite (Prosopis juliflora) pods and matira (Citrullus lanatus) seed cake in complete ration on growth performance of kids. MVSc Thesis, Rajasthan Agriculture University, Bikaner, Rajasthan, (India).

Croissant G. et al., (1976). New Mexico State Univ. Agricult. Experiment station, Las Cruces.

Flint, H. J. (1994). Molecular genetics of obligate anaerobes from the rumen. FEMS Microbiol. Lett. 121: 259-267.

Forano, E. (1991). Recent progress in genetic manipulation of rumen microbes. In: Ruminant Microbial Metabolism and Ruminant Digestion (Ed. J. P. Jouany). INRA Editions, France, pp. 89-103.

Forsberg, C. W. et al., (1993). Establishment of rumen microbial gene pools and their manipulation to benefit digestion by domestic animals. In: Proceeding of the Seventh World Conference on Animal Production, Edmonton, Alberta, Vol. 1. pp. 281-316.

Fuller, R., (1989). Probiotics in man and animals. A review. Journal of Applied Bacteriology, 66, 365-378.

Gupta, S. and Savalia, C.V. (2012). Application of biotechnology to improve livestock products. A review. Vet. World, 2012, Vol.5 (10): 634-638. doi: 10.5455/vetworld. 2012.634-638.

Jouany, J.P. (1994). Methods of manipulating the microbial metabolism in the rumen. Ann Zootech (1994) 43, 49-62.

Kahi A.K. and Rewe T.O. (2008). Biotechnology in livestock production: Overview of possibilities for Africa. African J. of Biotech 7: 4984-4991. 
Kim, J. H. et al., (1985). Cellulose production by solid state fermentation system. Biotech. And Bioenge. 27:1450-1454.

Lebbie S.H.B. and Kagwini E., (1996). Small Ruminant Research and Development in Africa. Proceedings of the Third Biennial Conference of the African Small Ruminant Research Network, UICC, Kampala, Uganda, 5-9 December 1994. ILRI (International Livestock Research Institute) Nairobi, Kenya. 326 pp.

Leng R.A., (1991). Application of biotechnology to nutrition of animals in developing countries. FAO, Animal Production And Health Paper 90.

McDonald P. et al., (2010). Animal Nutrition. Pearson Books.

McGuffey R. K., et al., (2001). Ionophores for Dairy Cattle: Current Status and Future Outlook. J. Dairy Sci. 84 (E. Suppl.): E 194E 203.

McSweeney, C. S., et al., (1999). The application of rumen biotechnology to improve the nutritive value of fibrous feed stuffs: pre and post ingestion. Livest. Prod. Sci. 59:265-283.

Negi, S.S., et al., (1989). In situ rumen degradation of dry matter and nitrogen in some concentrate feed supplements. Indian J. Anim. Sci., 61: 1-12.

Phipps R. H., et al., (2005). Effect of Corn Silage from an Herbicide-Tolerant Genetically Modified Variety on Milk Production and Absence of Transgenic DNA in Milk. J. Dairy Sci. 88: 2870-2878.

Sahoo, A. and Jena, B. (2014). Designer egg and meat through nutrient manipulation. Review article. Journal of Poultry Science and Technology. July-September, 2014, 2(3): 3847.

Santra, A. And Karim, S.A. (2003). Rumen Manipulation to Improve Animal
Productivity. Asian-Aust. J. Anim. Sci. 2003. Vol 16, No. 5: 748-763.

Shelke, S.K. and S.S. Thakur, (2011). Effect on the quality of milk and milk products in murrah buffaloes (Bubalus bubalis) fed rumen protected fat and protein. Int. J. Dairy Sci., 6: 124-133.

Shelke, S.K. et al., (2012). Protected nutrients technology and the impact of feeding Protected nutrients to dairy animals: A review. Int. J. Dairy Sci., 7(3): 51-62, 2012.

Smith, C.J. and R. B. Hespell. (1983). Prospects for the development and use of recombinant deoxyribonucleic acid techniques with ruminal bacteria. J. Dairy Sci. 66:1536-1546.

Spangenberg G. et al., (2001). Transgenesis and genomics in molecular breeding of forage plants. Retrieved 16 January, 2014, from the World Wide Web: http://www.regional. org.au/au/asa/2001/plenery/6/spangenberg.ht $\mathrm{m}$.

Vinus and Sheoran, N. (2017). Role of Nanotechnology in Poultry Nutrition. Int. J. Pure App. Biosci. 5 (5): 1237-1245 (2017).

Wael G. Fahmy, et al., (1998). Effect of Defaunation and Amino Acid Supplementation on Growth and Amino Acid Balance in Sheep. University of Illinois Extension, available at http://www.livestocktrail.illinois.edu/dairyne t/paperDisplay.cfm?ContentID $=238$ accessed on 13/03/2013.

Wallace, R. J. (1994). Rumen microbiology, biotechnology and ruminant nutrition: prospects and problems. J. Anim. Sci. 72: 2992-3003.

Walli, T.K., (2005). Bypass protein technology and the impact of feeding bypass protein to dairy animals in tropics: A review. Indian J. Anim. Sci., 75: 135-142.

\section{How to cite this article:}

Dharmendra Chharang, Vijay Prakash Saini, Deepak Chopra and Sheela Choudhary. 2019. Current and Future Perspective of Biotechnological Applications in Livestock Nutrition: A Review. Int.J.Curr.Microbiol.App.Sci. 8(06): 973-982.

doi: https://doi.org/10.20546/ijcmas.2019.806.118 